\title{
Iota Toxin, S Toxin and CDT: Members of the Same Class of Clostridial Binary Toxins in Feces of Humans and Other Animals
}

\author{
Robert J. Carman*, Adam L. Stevens, Christopher W. Genheimer and Tracy D. Wilkins
}

TechLab, Inc., 2001 Kraft Drive, Blacksburg, VA 24060-6358, USA

\begin{abstract}
Some strains of Clostridium perfringens, Clostridium spiroforme and Clostridium difficile produce binary toxins known respectively as iota toxin, $\mathrm{S}$ toxin and CDT. Each toxin consists of two unlinked polypeptides (e.g. CDTa and $\mathrm{CDTb}$ ) that only together have biological activity. Taking an historical perspective, we review the development and early use of assays employing the specific neutralization of a biological activity for the detection and quantification of binary toxin. The survey moves on to more recent immunological assays and culminates with a discussion of the relevance of binary toxin, especially CDT, in feces.
\end{abstract}

Keywords: Clostridium perfringens, Clostridium difficile, Clostridium spiroforme, iota, CDT, binary toxin, enterotoxin, diarrhea.

\section{INTRODUCTION}

Iota toxin and its close relatives, $\mathrm{S}$ toxin and $\mathrm{CDT}$, are binary toxins produced by Clostridium perfringens Type E, Clostridium spiroforme and Clostridium difficile, respectively. Essential properties of the toxins and their corresponding genes have been reviewed in the past [1]. Each toxin is produced as two unrelated separate gene products, one an enzyme, the other a cell-binding / membrane translocation factor. In the case of iota toxin, the two components are called iota a (ia) and iota b (ib). This convention is followed for $\mathrm{S}$ toxin and CDT, thus their respective components are designated as $\mathrm{Sa}$ and $\mathrm{Sb}$, plus $\mathrm{CDTa}$ and CDTb. The binding component of binary toxins is secreted as a propeptide that requires proteolytic activation to its mature, active form. Activation from pro-ib to $i b$ and from pro- $\mathrm{Sb}$ to $\mathrm{Sb}$ occurs in culture fluids, but pro- $\mathrm{CDTb}$ is not activated in vitro which likely reflects a paucity of serine-type proteases produced by $C$. difficile in culture, different cleavage sites, or both. Exogenous trypsin is required for the activation of pro-CDTb [2]. Mature binding component rapidly oligomerizes on the surface of a target cell to form a heptameric, donut-shaped channel through which the enzyme enters the cell (following endosome acidification) and mono-ADP-ribosylates globular actin, thus killing the cell by disrupting its cytoskeleton and particularly filamentous actin formation [1,3]. Neither component by itself has toxic activity, though individually each retains its respective binding and enzymatic properties.

Clostridial binary toxins are biologically active in various animal models. They kill mice when injected intraperitoneally and are dermonecrotic when injected intradermally

*Address correspondence to this author at TechLab, Inc., 2001 Kraft Drive, Blacksburg, VA 24060-6358, USA; Tel: (540) 953 1664;

Fax: (540) 953 1665; E-mail: rjcarman@techlab.com into the flanks of guinea pigs (Fig. 1) [4]. The binary toxins are enterotoxic and cause fluid to accumulate in ligated ileal loops of rabbits (Fig. 2) [5], an assay originally developed by workers studying cholera toxin and its activity. Clostridial binary toxins are readily cytotoxic to cultured cells [6]. All of these activities can be neutralized by antiserum to one or both of the binary components. Additionally, each component is also cross neutralized by antiserum to the individual components of the other binary toxins. Thus anti-iota toxin neutralizes $\mathrm{S}$ toxin of $C$. spiroforme and anti-Sb will neutralize $C$. perfringens iota toxin, etc. Such results suggest a high degree of structural similarity between the iota and iota-like toxin components produced by various clostridial species, which are all involved in enteric diseases of humans and other animals. Furthermore, it has been shown by different groups that chimeric toxins (i.e. $\mathrm{Sb}+\mathrm{ia}$, ib $+\mathrm{Sa}$, etc.) formed from mixing heterologous components are biologically active [7].

In this short review, we will compare and contrast the assays used to detect binary toxins. An historical approach will be taken that progresses from assays for the biological activities of $C$. perfringens Type $\mathrm{E}$ iota toxin, the first clostridial binary toxin to be discovered, through today and the very latest immunological assays for $C$. difficile $\mathrm{CDT}$. We will discuss what the presence of the binary toxins in feces means for the host.

\section{3-1980: CLOSTRIDIUM PERFRINGENS TYPE E IOTA TOXIN, MOUSE LETHALITY AND DER- MONECROSIS}

Iota toxin was first described as a cause of diarrhea in week-old calves [8]. Symptomatic animals had sterile stool filtrates that were toxic to mice when given by an intraperitoneal injection. Toxigenic isolates of $C$. perfringens were recovered from the same material and homologous antitoxin was subsequently raised. This antitoxin neutralized the toxic activity in fecal samples and culture fluids of $C$. perfringens. The toxin that caused this activity was named 


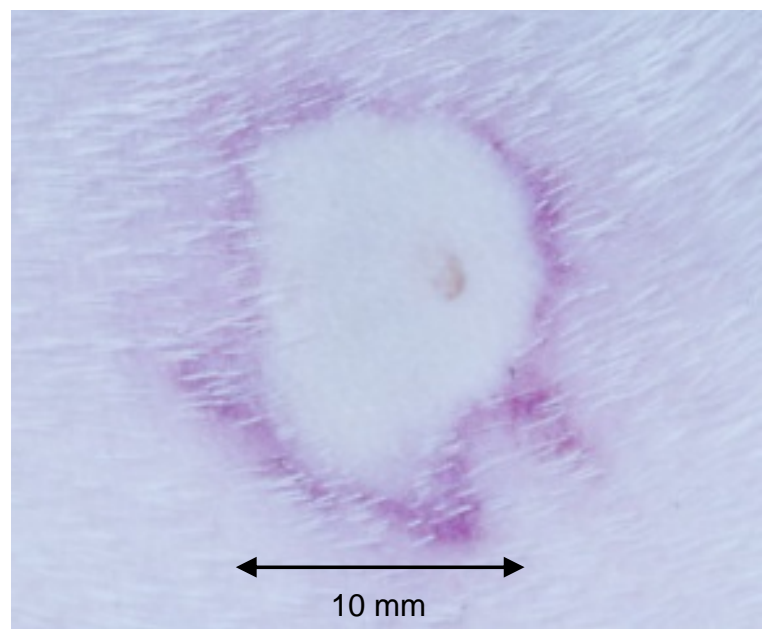

\section{Sa $(0.3 \mu \mathrm{g})$ and $\mathrm{Sb}(2.7 \mu \mathrm{g})$ in $0.3 \mathrm{~mL}$ injected intradermally}

Fig. (1). Dermonecrosis lesion on the shaven flank of a guinea pig caused by C. spiroforme $\mathrm{S}$ toxin after $24 \mathrm{~h}$.

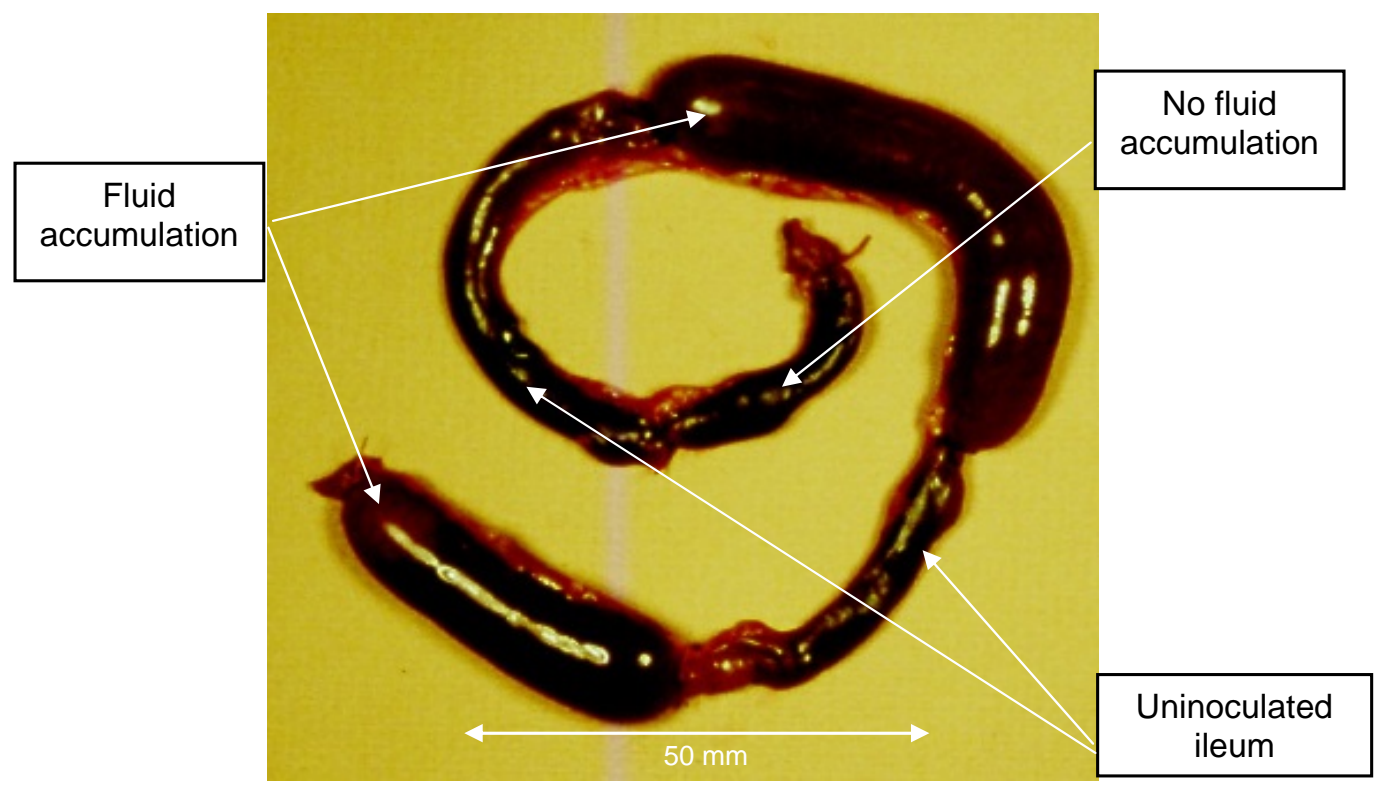

Sa $(1 \mu \mathrm{g})$ and $\mathrm{Sb}(9 \mu \mathrm{g})$ injected in $1 \mathrm{~mL}$ into each positive rabbit ileal loop

Fig. (2). Enterotoxic activity of $C$. spiroforme $\mathrm{S}$ toxin in rabbit ligated ileal loops.

iota toxin [9], and it became one of the four major toxins (i.e. alpha, beta, epsilon and iota) produced during log-phase growth that are now used to classify $C$. perfringens isolates as Type A, B, C, D or E. Thus, iota-producing strains were classed as Type E, and, while some Types make several toxins, only Type E isolates make iota toxin [4]. In 1986, Stiles and Wilkins $[10,11]$ showed iota to be a binary toxin, consisting of ia (the enzymatic mono-ADPribosyltransferase) and ib (cell binding/membrane translocation component). Stiles and his colleagues [12] went on to show that ib forms oligomers on the cell surface through which ia passes into the cell, where it disrupts actin monofilament formation.

For about 40 years, neutralizing the mouse-killing activity of iota toxin was both the means to detect iota toxin in feces and identify Type $\mathrm{E}$ isolates that make toxin in vitro.
A full typing assay for all the major toxins of $C$. perfringens was simply and comprehensively described by Sterne and Batty [4]. Their protocol is still used and has remained unchanged in anything but the finest of details. The set of four antitoxins, including Type $\mathrm{E}$ antitoxin needed for the assay, were sold in the 1970 s by the Wellcome Research Laboratories, Beckenham, England. This antitoxin gradually became unavailable, starting in the 1980s. No new reliable commercial source has emerged since. In veterinary circles, particularly when mouse lethality is used to detect iota toxin, neutralization is nowadays accomplished with a research-use only reagent. If a mouse-killing, filterable toxin is detected and no neutralization is attempted (say from the want of a suitable antitoxin), PCR assays for $i a, i b$ or both are used to make a diagnosis. However, such genetic-based diagnosis say nothing about the actual toxin production in situ that is, ultimately, responsible for disease. 
There have been few diagnostic studies of the levels of iota toxin required for activity, and none connect toxin levels with disease severity. Obviously, when diarrhea is diagnosed by the mouse assay, a sample must contain at least 1 mouse lethal dose (MLD). This though is probably a gross underestimation. In a titration of highly purified ia and ib, $0.025 \mathrm{nmol}$ of each $(1.25 \mu \mathrm{g}$ and $1.88 \mu \mathrm{g}$, respectively) represented 1 MLD when injected intraperitoneally [10]. Lower amounts were not always toxic (e.g. $0.013 \mathrm{nmol}$ of each component killed only half the mice). 0.62 pmol of each (i.e. 40-fold less than 1 MLD) was not lethal to mice yet remained dermonecrotic in guinea pigs; $0.31 \mathrm{pmol}$ had no activity in either assay. When the ib level was held constant but in excess ( $2.8 \mathrm{pmol}, 200 \mathrm{ng}$ ) and ia was titrated, dermonecrosis was still present at ia levels of 0.088 pmol (4 $\mathrm{ng}$ ). The cytoxicity and enterotoxicity of purified iota toxin have not been properly titrated to date, or at least not reported in the literature.

On occasions, iota toxigenic isolates are found in the feces of healthy livestock [8]. It is possible that, on occasions, this represents a carrier state in which there was no in vivo production at all in these animals and that is why the animals were asymptomatic. Equally, extremely low levels (less than 1 MLD) of iota toxin may have been present, but being that low, the animals were unaffected. In any event, these examples of discrepant findings (no toxin, only toxigenic bacteria) will be no better served by PCR (no toxin, only potentially toxigenic bacteria). Of course with spore formers like clostridia, the amplification of a particular toxin gene may represent nothing more than transient spores, not colonization, with vegetative cell division equating to a persistent carrier state.

\section{TO 1986: CLOSTRIDIUM SPIROFORME S TOXIN AND MOUSE LETHALITY, DERMONECRO- SIS, ILEAL LOOPS AND CYTOTOXICITY}

The $\mathrm{S}$ toxin of $C$. spiroforme was the second binary toxin to be characterised. It is closely related to $C$. perfringens iota toxin $[5,14]$. S toxin is the cause of a mainly post-weaning diarrhea of rabbits that is often fatal $[15,16]$. There are cases of unintended antibiotic-associated C. spiroforme diarrhea in rabbits [17]. Following clindamycin treatment, rabbits have been used to show $C$. spiroforme fulfilled Koch's postulates [18] and to study the course of the disease over time [19]. More recently $\mathrm{S}$ toxin-producing $C$. spiroforme has been isolated from horses with diarrhea (Unpublished data).

$\mathrm{S}$ toxin has all the same activities as iota toxin. It is mouse lethal, dermonecrotic, enterotoxic, and cytotoxic [5, $6,20,21]$. Mouse killing and dermonecrosis - both modified from protocols in Sterne and Batty [4] - have routinely been the assays used to make a laboratory diagnosis. Thus, the initial reports of $C$. spiroforme diarrhea in rabbits were made by neutralizing the mouse-killing activity with antitoxin to C. perfringens Type E. Before the first reports of $\mathrm{S}$ toxin production by $C$. spiroforme from diarrheic rabbits, this cross neutralization led to the understandable but erroneous conclusion that $C$. perfringens Type $\mathrm{E}$ was the source of the toxin [16, 21-25]. However, in all of these cases, $C$. perfringens Type $\mathrm{E}$ was never isolated from diseased animals yet a curiously-coiled bacterium (C. spiroforme) was evident in only the sick, but not healthy, animals.
To date, there is very limited data on biological activity levels of purified $\mathrm{Sa}$ and $\mathrm{Sb}$, and we know of only one quantitative assessment of $\mathrm{S}$ toxin levels in diarrheic feces. Thus, in a titration of $\mathrm{Sa}$ and $\mathrm{Sb}$ in combination, $100 \mathrm{ng}$ of each represented 1 MLD [26]. This was approximately tenfold lower than that reported for iota toxin $[10,11]$. An important question then becomes, in a titration just what should be the ratio of ia to ib? Should ia and ib be titrated in combination or individually, but still remain as a mix with only one component changing in concentration? If the latter, what should the level be for the untitrated component? These considerations apply equally to all assays involving biological activity of binary toxins

Carman \& Borriello [19] titrated the mouse lethal activity of $\mathrm{S}$ toxin in 5 rabbits experimentally infected with $C$. spiroforme. They injected mice with serial two-fold dilutions of filtrates from digesta collected at fixed time intervals via a cecal cannula. The bacterium was detected within 5 to $10 \mathrm{~h}$ of challenge, and about 5 to $10 \mathrm{~h}$ before $\mathrm{S}$ toxin had become detectable. Diarrhea began 15 to $20 \mathrm{~h}$ or so post challenge. In 3 animals, diarrhea and $\mathrm{S}$ toxin appeared simultaneously at $19 \mathrm{~h}$. The mouse lethal titers from digesta of these 3 animals were respectively $1 / 1,1 / 1$, and $1 / 4$, suggesting that 1 to 4 $\mathrm{MLD} / \mathrm{mL}$ may approximate 1 enterotoxic dose of $\mathrm{S}$ toxin. If this is so, it is hardly surprising that a mix of $\mathrm{Sa}(1 \mu \mathrm{g})$ and $\mathrm{Sb}(9 \mu \mathrm{g})$ injected into rabbit ileal loops was enterotoxic [5] , as it would have represented 10 or possibly more MLDs in Popoff's hands [26].

\section{TO PRESENT: CLOSTRIDIUM DIFFICILE CDT AND ELISAS}

While studying the enzymatic activities of toxigenic $C$. difficile, Popoff and his group [27] found an ia-like ADPribosyltransferase in the culture fluids of $C$. difficile 196, an historical isolate from a human with diarrhea. The same group [28] went on to show, using immunoblots and cytotoxicity, the production of enzymatic and binding components for a binary toxin that they called CDT and found it to be very similar to both iota and S toxins at the functional, genetic and immunological levels. They also showed that in $C$. difficile, expression of cytotoxic levels of CDT was approximately forty-fold lower than that for $C$. perfringens iota toxin, a finding since confirmed by others [2]. A low level of transcription, not loss of specific activity from synthesized toxin components, explained the shortfall in CDT activity [27]. In fact while $c d t R$ has been shown to regulate CDT expression in $C$. difficile [29], PCR and bioinformatics reveal that an equivalent $c d t R$ is absent from both $C$. spiroforme and $C$. perfringens (Unpublished data). Each of the three binary toxin producers has an upstream sequence distinct from the others, pointing to possibly three distinct mechanisms of regulation. In many ways this is a remarkable twist on evolution, as at the protein level these clostridial binary toxins are very similar in various ways.

In about 2000, the effects of changes in the use of fluoroquinolone antibiotics began to manifest themselves in hospitals as an emerging resistance among $C$. difficile isolates to moxafloxacin. Though many different strains had become resistant, one in particular, ribotype 027, was identified as the dominant epidemic strain in several outbreaks worldwide [30,31]. Previous outbreaks of $C$. 
difficile had often been associated with the development of resistance to a particular antimicrobial agent. There have been other $C$. difficile outbreaks linked to clindamycin resistance, and others linked to resistance to cephalosporins. While resistance to widely used fluoroquinolone may help explain the recent frequency of cases, it probably has less to do with the parallel rise in the severity of $C$. difficile 027 disease reported by some but not others. Any link between severity of symptoms and 027 infections thus requires another explanation. There is the deregulation of toxins A and $\mathrm{B}$ expression during early log-phase growth in the test tube that is assumed to translate to increased toxin production in vivo. This is probably caused not by the widely reported deletions in the down regulator, $t c d C$, but by the less well-known stop codon resulting from a point mutation. Then there is CDT.

Ribotype 027 isolates carry $c d t A, \quad c d t B$, and the regulatory gene, $c d t R$. All 3 are required for a functional CDT locus. Some non-CDT producing isolates carry a ghost locus, consisting of the entire $c d t R$ but only parts of $c d t A$ and $c d t B$. Most researchers have used the PCR technique to show the carriage of $c d t A, c d t B$, or both. Though many authors have, using PCR, identified many isolates that carry the CDT locus, very few have shown in vitro production of CDT by ribotype 027 isolates. When production is assayed, it is generally through immunoblotting and guinea pig dermonecrosis whenever proof of biological activity was needed. Titrations and firm quantitation of CDT in feces have not been reported.

Geric and her colleagues [2] studied CDT from IS 58, an otherwise non-toxic isolate that lacks genes for the large clostridial toxins A and B. IS 58 made low levels of CDT that were enterotoxic and required exogenous trypsin for activation, possibly because the peptidase cleavage site differs between pro-CDTb versus pro-Sb and pro-ib. Additionally, the protease activities of $C$. difficile may be inadequate compared to those in $C$. perfringens Type $\mathrm{E}$ and $C$. spiroforme cultures. Whether or not activation occurs in vivo, perhaps via pancreatic or microbial proteases provided by other bacterial flora, is not known. Possibly then, the want of activation coupled with a low level of expression may help explain why clindamycin-treated hamsters do not have diarrhea despite colonization by IS 58 [2].

In an unpublished study, TechLab used an enzyme immunoassay to detect $\mathrm{CDTb}$, the binding component of CDT, in antibiotic-associated diarrheal samples from humans and from which $C$. difficile was cultured. By comparison with a standard curve, the estimated levels of fecal cdtB in 12 of 19 positive samples exceeded $100 \mathrm{ng} / \mathrm{mL}$. Thus, these 12 samples contained a level of CDTb that, had it been $\mathrm{Sb}$, would have been lethal to mice [26] and exceeded the level of $\mathrm{Sb}$ in cecal digesta from clearly diseased, diarrheic rabbits [19]. So, even if CDT does not have a direct role in $C$. difficile-induced diarrhea, it may reach levels that contribute more indirectly to the overall clinical picture, in a complementary way not seen with otherwise non-toxigenic isolates like IS 58.

\section{CONCLUSIONS}

As our knowledge of binary toxins has grown, techniques for their detection have become less dependent upon neutralization of biological activity and more so upon immunoassays, though none of the toxins are yet well served by a commercial assay. The role of iota and $S$ toxins in causing diarrhea is beyond dispute, but the minimum doses needed for activity are not known. A similar role for CDT remains unproven, though it is a distinct possibility as fecal levels from cases of human disease sometimes match the levels of $S$ toxin that occur in diarrheic animals. The correlation of CDT amounts with disease severity in humans should be addressed in future studies.

\section{Footnote Added During Preparation}

Shwan et al. [32] recently offered a new explanation of how CDT might enhance the virulence of $C$. difficile. They suggested that CDT induces the formation of microtubules that protrude from the intestinal epithelial cells. These microtubules form a dense mesh, rich in capture proteins, that wrap and embed $C$. difficile and effectively increase its attachment to and persistence on the host's epithelium.

\section{REFERENCES}

[1] Barth H, Stiles BG. Binary actin-ADP-ribosylating toxins and their use as molecular Trojan horses for drug delivery into eukaryotic cells. Curr Med Chem 2008; 15: 459-69.

[2] Geric B, Carman RJ, Rupnik M, et al. Binary toxin-producing, large clostridial toxin-negative Clostridium difficile strains are enterotoxic but do not cause disease in hamsters. J Infect Dis 2006; 193: 1143-50.

[3] Stiles BG, Hale ML, Marvaud JC, Popoff MR. Clostridium perfringens iota toxin: characterization of the cell-associated iota $\mathrm{b}$ complex. Biochem J 2002; 367: 801-8.

[4] Sterne M, Batty I. Pathogenic clostridia, Butterworths, London, 1965.

[5] Carman RJ, Stiles BG, Wilkins TD. Iota toxin produced by Clostridium spiroforme and Clostridium perfringens Type $\mathrm{E}$ is a synergistic combination of two proteins. In: Borriello SP, Hardie JM, Eds. Recent advances in anaerobic bacteriology. Dordrecht, Netherlands, Martinus Nijhoff Publishers 1987; pp. 312-4.

[6] Butt MT, Papendick RE, Carbone LG, Quimby FW. A cytotoxicity assay for Clostridium spiroforme enterotoxin in cecal fluid of rabbits. Lab Anim Sci 1994; 44: 52-4.

[7] Perelle S, Scalzo S, Kochi S, Mock M, Popoff MR. Immunological and functional comparison between Clostridium perfringens iota toxin, C. spiroforme toxin, and anthrax toxins. FEMS Microbiol Lett 1997; 146: 117-21.

[8] Bosworth TJ. On a new type of toxin produced by Clostridium welchii. J Comp Pathol 1943; 53: 245-55.

[9] Ross HE, Warren ME, Barnes JM. Clostridium welchii iota toxin: its activation by trypsin. J Gen Micrbiol 1949; 3: 148-52.

[10] Stiles BG, Wilkins TD. Purification and characterization of Clostridium perfringens iota toxin: dependence on two nonlinked proteins for biological activity. Infect Immun 1986a. 54: 683-8.

[11] Stiles BG, Wilkins TD. Clostridium perfringens iota toxin: synergism between two proteins. Toxicon 1986; 24: 767-73.

[12] Stiles BG, Hale ML, Marvaud JC, Popoff MR. Clostridium perfringens iota toxin: binding studies and characterization of cell surface receptor by fluorescence-activated cytometry. Infect Immun 2000; 68: 3475-84.

[13] Simpson LL, Stiles BG, Zepeda H, Wilkins TD. Production by Clostridium spiroforme of an iota like toxin that possesses mono(ADP-ribosyl)transferase activity: identification of a novel class of ADP-ribosyltransferases. Infect Immun 1989; 57: 255-61.

[14] Carman RJ, Borriello SP. Clostridium spiroforme isolated from rabbits with diarrhoea. Vet Rec 1982; 111: 342-3.

[15] Borriello SP, Carman RJ. Association of toxigenic Clostridium spiroforme with iota toxin positive enterotoxemia in rabbits. J Clin Microbiol 1983; 17: 414-8.

[16] Rehg JE, Pakes SP. Implication of Clostridium difficile and Clostridium perfringens iota toxins in experimental lincomycinassociated colitis of rabbits. Lab Anim Sci 1982; 32: 253-7. 
[17] Carman RJ, Borriello SP. Infectious nature of Clostridium spiroforme mediated rabbit enterotoxaemia. Vet Microbiol 1984; 9: 497-502.

[18] Carman RJ, Borriello SP. Studies on the progression of Clostridium spiroforme mediated diarrhoea using rabbits fitted with caecal cannula. Microb Ecol Health Dis 1988; 1: 109-14.

[19] Carman RJ, Borriello SP. Laboratory diagnosis of Clostridium spiroforme mediated diarrhoea of rabbits. Vet Rec 1983; 113: 1845 .

[20] La Mont JT, Sonnenblick EB, Rothman S. Role of clostridial toxin in the pathogenesis of clindamycin colitis in rabbits. Gastroenterology 1979; 76: 356-61.

[21] Katz L, LaMont JT, Trier JS, et al. Experimental clindamycinassociated colitis in rabbits. Evidence for toxin-mediated mucosal damage. Gastroenterology 1978; 74: 246-52.

[22] Orcutt RP, Foster HL, Jonas AM. Clostridium perfringens Type E enterotoxemia as the cause of acute diarrheal death or "hemorrhagic typhlitis" in rabbits: 1978: Proceedings of the Association of Laboratory Animal Science Association, Assoc Lab Anim Sci 1978, Abstract 100.

[23] Patton NM, Holmes HT, Riggs R J, Cheeke PR. Enterotoxemia in rabbits. Lab Anim Sci 1978; 28: 536-40.

[24] Baskervllle M, Wood M, Seamer JH. Clostridium perfringens type E enterotoxaemia in rabbits. Vet Rec 1980; 107: 18-9.

[25] Eaton P, Fernie DS. Enterotoxaemia involving Clostridium perfringens iota toxin in a hysterectomy derived rabbit colony. Lab Anim 1980; 14: 347-51.
[26] Popoff MR, Milward FW, Bancillon B, Boquet P. Purification of the Clostridium spiroforme binary toxin and activity of the toxin on HEp-2 cells. Infect Immun 1989; 57: 2462-9.

[27] Popoff MR, Rubin EJ, Gill DM, Boquet P. Actin-specific ADPribosyltransferase produced by a Clostridium difficile strain. Infect Immun 1988; 56: 2299-306.

[28] Perelle S, Gibert M, Bourlioux P, Corthier G, Popoff MR. Production of a complete binary toxin (actin-specific ADPribosyltransferase) by Clostridium difficile CD196. Infect Immun 1997; 65:1402-7.

[29] Carter GP, Lyras D, Allen DL, et al. Binary toxin production in Clostridium difficile is regulated by CdtR, a LytTR family response regulator. J Bacteriol 2007; 189: 7290-301.

[30] McEllistrem MC, Carman RJ, Gerding DN, Genheimer CW, Zheng L. A Hospital outbreak of severe Clostridium difficile disease associated with isolates carrying binary toxin genes. Clin Infect Dis 2005; 40: 265-72.

[31] McDonald LC, Killgore GE, Thompson A, et al. An epidemic, toxin gene-variant strain of Clostridium difficile. N Engl J Med 2005; 353: 2433-41.

[32] Schwan C, Stecher B, Tzivelekidis T, et al. Clostridium difficile toxin CDT induces formation of microtubule-based protrusions and increases adherence of bacteria. PLoS Pathog 2009; 5(10): Epub 2009 Oct 16.

(c) Carman et al.; Licensee Bentham Open.

This is an open access article licensed under the terms of the Creative Commons Attribution Non-Commercial License (http: //creativecommons.org/licenses/bync/3.0/) which permits unrestricted, non-commercial use, distribution and reproduction in any medium, provided the work is properly cited. 